\title{
Hormonal and gene dynamics in de novo shoot meristem formation during adventitious caulogenesis in cotyledons of Pinus pinea
}

\author{
José M. Alvarez ${ }^{1}$ D $\cdot$ Natalia Bueno $^{1} \cdot$ Candela Cuesta $^{1}$ (D) $\cdot$ Isabel Feito ${ }^{2}$ (D) Ricardo J. Ordás $^{1}$ (D)
}

Received: 29 October 2019 / Accepted: 8 January 2020 / Published online: 28 January 2020

(c) The Author(s) 2020

\begin{abstract}
Key message Several members of WOX and KNOX gene families and several plant growth regulators, basically cytokinins and auxins, play a key role during adventitious caulogenesis in the conifer Pinus pinea.

Abstract Similar to Arabidopsis thaliana, Pinus pinea shoot organogenesis is a multistep process. However, there are key differences between both species, which may alter the underlying physiological and genetic programs. It is unknown if the genic expression models during angiosperm development may be applicable to conifers. In this work, an analysis of the endogenous content of different plant growth regulators and the expression of genes putatively involved in adventitious caulogenesis in $P$. pinea cotyledons was conducted. A multivariate analysis of both datasets was also realized through partial least squares regression and principal component analysis to obtain an integral vision of the mechanisms involved in caulogenesis in P. pinea. Analyses show that cotyledons cultured in the presence of benzyladenine during long times (2-6 days) cluster separately from the rest of the samples, suggesting that the benzyladenine increase observed during the first hours of culture is sufficient to trigger the caulogenic response through the activation of specific developmental programs. In particular, the most relevant factors involved in this process are the cytokinins trans-zeatin, dihydrozeatin, trans-zeatin riboside and isopentenyl adenosine; the auxin indoleacetic acid; and the genes PpWUS, PpWOX5, PpKN2, PpKN3 and PipiRR1. WUS is functional in pines and has an important role in caulogenesis. Interestingly, WOX 5 also seems to participate in the process, although its specific role has not been determined.
\end{abstract}

Keywords De novo shoot organogenesis $\cdot$ Conifers $\cdot$ Plant growth regulators $\cdot$ Gene expression $\cdot$ Multivariate analyses

Communicated by Attila Feher.

José M. Alvarez and Natalia Bueno contributed equally to this work.

Electronic supplementary material The online version of this article (https://doi.org/10.1007/s00299-020-02508-0) contains supplementary material, which is available to authorized users.

Ricardo J. Ordás

rordas@uniovi.es

1 Instituto Universitario de Biotecnología de Asturias, Departamento de Biología de Organismos y Sistemas, Universidad de Oviedo, Oviedo, Spain

2 Servicio Regional de Investigación Y Desarrollo Agroalimentario de Asturias (SERIDA), Villaviciosa, Spain

\section{Introduction}

The formation of adventitious shoots is a complex process that involves the participation of plant growth regulators (PGRs), mainly auxins and cytokinins, with multiple signaling pathways (Kareem et al. 2016; Sang et al. 2018; Tian et al. 2018; Ikeuchi et al. 2019). Three phases have been differentiated during the in vitro caulogenic process: acquisition of morphogenic competence (associated with certain level of cellular dedifferentiation or transdifferentiation); induction of cell identity specification for shoot apical meristem (SAM) formation in response to exogenous PGRs; and shoot development (Christianson and Warnick 1983).

De novo shoot organogenesis has been deeply studied in the model plant Arabidopsis (Arabidopsis thaliana L. Heynh). In this organism, in vitro caulogenesis is an indirect process, as it is achieved through a two-step regeneration protocol that involves the culture of root explants in an auxin-rich callus induction medium (CIM) followed by the 
incubation of explants in a cytokinin-rich shoot induction medium (SIM) (Valvekens et al. 1988; reviewed in Ikeuchi et al. 2019). During CIM incubation, explants progressively acquire competence to respond to the induction stimuli, while within SIM incubation, explants become competent to differentiate into shoots. During these phases, auxin and cytokinin response signals in a mutually exclusive pattern (Sang et al. 2018). In callus masses, the activation of a cytokinin response domain was reported, as type-B ARABIDOPSIS RESPONSE REGULATOR (ARR) transcription factors such as ARR1, ARR10, and ARR12 directly suppress YUCCA4 (YUC4) expression and prevent auxin biosynthesis (Meng et al. 2017). As a result, members of the class III homeodomain-leucine zipper (HD Zip III) transcription factors directly interact with type-B ARRs and induce the expression of WUSCHEL (WUS) in a selected group of cells, which specifies stem cell fate in the center of the regenerating shoot meristem (Meng et al. 2017; Zhang et al. 2017; Zubo et al. 2017). Afterward, these HD Zip III proteins upregulate other genes that play key roles in the SAM formation and maintenance such as the class I KNOX gene SHOOT MERISTEMLESS (STM) (Shi et al. 2016). Altogether, these processes promote the transition from callus cells into shoot stem cells giving rise to de novo establishment of SAMs.

De novo shoot organogenesis protocols have been also developed in other plant groups such as conifers. In Pinus spp., in vitro caulogenesis induction is easily obtained in cotyledons detached from non-germinated mature embryos cultured in the presence of a cytokinin, usually benzyladenine (BA) (Flinn et al. 1988; López et al. 1996). This technique has been used for clonal plant production in some species such as stone pine (Pinus pinea L.), a Mediterranean native species that has been economically exploited for its edible seeds or pine nuts (González et al. 1998; Valdés et al. 2001; Moncaleán et al. 2005; Alonso et al. 2006; Cortizo et al. 2009; Cuesta et al. 2009). Apart from its use in breeding programs, $P$. pinea has been proposed as a model for the study of the physiological and molecular basis of caulogenesis in conifers (Cuesta et al. 2009). Unlike Arabidopsis, in vitro caulogenesis in $P$. pinea is an example of direct organogenesis, as cotyledons are competent per se and respond to the induction signal (consisting in the addition of a single PGR to the induction medium), without an intermediate callus formation in a very synchronous fashion (Cuesta et al. 2009). Several studies have shown that the endogenous hormonal content of $P$. pinea cotyledons determined the organogenic capacity (Valdés et al. 2001; Moncaleán et al. 2005; Cortizo et al. 2009; Cuesta et al. 2012). Cotyledons excised from germinated embryos showed a lower organogenic capacity than those excised from non-germinated embryos, which was associated with a reduction in active cytokinins and indoleacetic acid (IAA) endogenous levels (Valdés et al. 2001). Furthermore, the evaluation of the organogenesis response in selected half-sibling families showed that this process is genotype dependent (Cuesta et al. 2008), being connected with the cytokinin content, which significantly differed between families with opposite caulogenesis parameters (Cuesta et al. 2012).

Despite the available information about hormonal content, the knowledge about the underlying molecular mechanisms of de novo shoot formation in conifers, both in vitro and in planta is still limited. Previous studies have characterized in $P$. pinea a type-A response regulator (PipiRRl) involved in the cytokinin signal transduction pathway and a leucine-rich-repeat protein receptor kinase gene (Pipi$C L V 1 L$ ) that shows homology with CLAVATAl (CLVI) gene from Arabidopsis, a member from the central pathway involved in SAM homeostasis maintenance. Even more, both genes are upregulated in the presence of BA during in vitro caulogenesis (Cortizo et al. 2010; Alvarez et al. 2013).

Increasing availability of data on the genome and transcriptome of several gymnosperms facilitates the study of genes involved in SAM formation and maintenance. A recent study in Pinus pinaster showed for the first time that conifers contain functional discrete WUS and WUSCHEL-RELATED HOMEOBOX 5 (WOX5) orthologs expressed in SAM and root apical meristem (RAM), respectively, suggesting that these genes might play similar roles to those described for their Arabidopsis counterparts (Alvarez et al. 2018). Furthermore, the analysis of $K N O X$ gene family in $P$. pinaster (Bueno et al., unpublished work) allowed the identification of four class I KNOX genes ( $P p K N 1-P p K N 4$ ), in concordance with several pine and spruce species reports, which showed, based on expression studies and transformation experiments, a similar role in SAM functioning compared to their angiosperm counterparts (Sundås-Larsson et al. 1998; Hjortswang et al. 2002; Guillet-Claude et al. 2004; Belmonte et al. 2007; Larsson et al. 2012).

Our starting work hypothesis is that SAM formation and stem development is a conserved process in the evolution of seed plants and therefore the model proposed for Arabidopsis can be extrapolated to gymnosperms. To contrast this hypothesis, we will need to deepen our knowledge on the physiological and molecular factors involved in the shoot formation in gymnosperms. Plant development is the result of the homeostasis of all endogenous PGRs, with greater or lesser importance of one or the other in each of the processes involved. The experiments performed by Skook and Miller (1957) already showed that cytokinins and auxins play a key role in the induction and development of shoots in tissues grown in vitro. Until recently, most studies focused on these phytohormones as the main modulators of in vitro caulogenesis. However, it is known that all PGRs interact among themselves modifying their responses in a mechanism called cross talk (Skalický et al. 2018). In addition, the preparation of 
in vitro explants and culture conditions are stressful and, therefore, could modulate hormonal homeostasis. For that reason, in this work we analyzed the endogenous content of several PGRs from different classes of plant hormones, including cytokinins, gibberellins, brassinosteroids, auxins and stress-related PGRs, such as abscisic and salicylic acid, and jasmonates, during the induction phase of de novo shoot formation in $P$. pinea. We also conducted the expression profile analysis of several genes that putatively participate in the signaling pathways involved in SAM formation and maintenance in conifers (several WOX and KNOX members, PipiRR1 and PipiCLVIL) along this process. In particular, we compared hormonal and gene expression dynamics in BA-treated and non-treated cotyledons to elucidate their involvement in this process. Multivariate analyses were carried out to integrate PGRs dynamics and gene expression analysis during the organogenic process.

\section{Material and methods}

\section{Explant source and culture conditions}

One-year-old mature seeds from open-pollinated Pinus pinea trees growing in natural stands were used in this study. Seeds from "ES01 Meseta Norte" provenance were provided by "Servicio de Material Genético del Ministerio de Medio Ambiente" (Spain). After removing the seed coat, megagametophytes were surface sterilized by immersion in $7.5 \%(\mathrm{v} / \mathrm{v}) \mathrm{H}_{2} \mathrm{O}_{2}$ for $45 \mathrm{~min}$, followed by three rinses in sterile double-distilled water, with a final imbibition step in moistened sterile paper for $48 \mathrm{~h}$ at $4{ }^{\circ} \mathrm{C}$ in darkness.

Cotyledons were then excised from embryos and placed horizontally in $200-\mathrm{mL}$ baby food jars containing $20 \mathrm{~mL}$ of Lepoivre medium modified by Aitken-Christie et al. (1988) with half-strength macroelements and supplemented with 3\% (w/v) sucrose, $0.8 \%(\mathrm{w} / \mathrm{v})$ agar (Duchefa, $\mathrm{NL}$ ) and a final concentration of $44.4 \mu \mathrm{M}$ BA (Duchefa, $\mathrm{NL}$ ), adjusting $\mathrm{pH}$ to 5.8 before autoclaving (Cuesta et al. 2009). Cotyledons cultured in the same medium without BA were used as control. Cultures were maintained in a growth chamber at $25 \pm 2{ }^{\circ} \mathrm{C}$ with a 16 -h photoperiod at a photon flux of $20 \pm 5 \mu \mathrm{mol} \mathrm{m}{ }^{-2} \mathrm{~s}^{-1}$.

Batches of about 30 cotyledons cultured in the presence and absence of BA (hereafter BA-treated and control cotyledons, respectively) were harvested after different times of culture $(0,0.25,0.5,1,2,4$ and 6 days), rinsed with distilled water, drained with filter paper, immediately frozen in liquid nitrogen and stored at $-80{ }^{\circ} \mathrm{C}$ until analysis was carried out. Experiments were repeated three times.
Quantification of plant growth regulators (PGRs) during adventitious caulogenesis in Pinus pinea

\section{PGR extraction}

The extraction of multiple PGRs (abscisic acid, ABA; indoleacetic acid, IAA; benzyladenine, BA; castasterone, BK; dihydrozeatin, DHZ; dihydrozeatin riboside, DHZR; gibberellin $\mathrm{GA}_{4}$; isopentenyl adenine, $\mathrm{iP}$; isopentenyl adenosine, iPA; jasmonic acid, JA; salicylic acid, SA; trans-zeatin, $\mathrm{tZ}$; and trans-zeatin riboside, tZR) was performed following the protocol described by Delatorre et al. (2017). Samples from pooled cotyledons (100 mg of fresh weight were homogenized in liquid $\mathrm{N}_{2}$ in a bead mill homogenizer Silamat S6 (Ivoclar Vivadent, Spain) and re-suspended in $1 \mathrm{~mL}$ of extraction buffer (2-propanol/ $\mathrm{H}_{2} \mathrm{O} / \mathrm{HCl} 37 \%$ 2:1:0.002, $\mathrm{v} / \mathrm{v} / \mathrm{v}$ ) in 2-mL Safe Lock propylene tubes (Eppendorf Ltd, Germany). Internal standards $\mathrm{d}_{7}-\mathrm{BA}, \mathrm{d}_{3}-\mathrm{DHZ}$ (3.75 ng); $\mathrm{d}_{6}$-SA (7.5 ng); $\mathrm{d}_{6}-\mathrm{ABA}, \mathrm{d}_{5}-\mathrm{IAA}, \mathrm{d}_{2}-\mathrm{GA}_{9}(15 \mathrm{ng})$; and $\mathrm{d}_{5}$-BK (30 ng) were added at this point to assess recovery rates. All of them were supplied by Olchemim Ltd. (Czech Republic) except $\mathrm{d}_{6}$-SA (Sigma Aldrich, St. Louis, MO, USA).

After agitating by repeated inversion $(60 \mathrm{rpm})$ for $30 \mathrm{~min}$ at $4{ }^{\circ} \mathrm{C}$ in the dark, the resulting suspension was transferred to Teflon tubes (Oak Rifge Centrifuge Tube, Thermo Scientific, England) and $1.8 \mathrm{~mL}$ of dichloromethane was added, agitating for an additional $30 \mathrm{~min}$ at the same conditions. The organic lower layer was collected and a re-extraction of the upper phase was carried out. The organic phase was then concentrated in 2-mL glass vials under $\mathrm{N}_{2}$ flow and stored at $-20^{\circ} \mathrm{C}$ until analysis.

\section{Quantification by QQQ-MS/MS}

The resulting dried extracts were resuspended in $150 \mu \mathrm{L}$ of $100 \%$ methanol by vortexing (1 $\mathrm{min})$ and sonication $(5 \mathrm{~min})$ and filtered through a $0.2 \mu \mathrm{m}$ regenerated cellulose Captiva Premium Syringe filter (Agilent Technologies, California, USA). All compounds were separated and quantified by ultrahigh performance liquid chromatography coupled with tandem mass spectrometry detectors (UHPLC-MS/MS) in a 6460 Triple Quad LC/MS (Agilent Technologies) following the protocol described by Delatorre et al. (2017). A chromatographic separation was made using a reverse phase column (Zorbax SB-C18 2.1 $\times 50 \mathrm{~mm}$ column). The column was held at $40{ }^{\circ} \mathrm{C}$ and the mobile phase used in the chromatography consisted of (A) $99.9 \% \mathrm{MeOH}: 0.1 \% \mathrm{COOH}$ and (B) ammonium formate $(10 \mathrm{mM}, \mathrm{pH} 4)$. A linear gradient of $\mathrm{MeOH}$ from 10 to $50 \%$ and then reaching $100 \%$ in 7 and 2 min, respectively, was used for compound elution. PGRs were quantified by dynamic multireaction monitoring $(\mathrm{MRM})$ of their $[\mathrm{M}+\mathrm{H}]+$ and the appropriate product 
ions, using optimized cone voltages and collision energies for diagnosis of each PGR analyzed.

\section{PGR immunolocalization during adventitious caulogenesis in Pinus pinea}

\section{Cotyledon fixation and sectioning}

Fixation was performed as described by De Diego et al. (2013). Cotyledons cultured in the presence and absence of $44.4 \mu \mathrm{M}$ BA during $0,0.5,2$ and 6 days were immediately fixed for $24 \mathrm{~h}$ at $4{ }^{\circ} \mathrm{C}$ under vacuum in a fixation solution consisting of $4 \%(\mathrm{w} / \mathrm{v})$ paraformaldehyde, $4 \%$ (w/v) 1-ethyl3-(3-dimethyl-aminopropyl) carbodiimide (EDAC; SigmaAldrich Co., St Louis, MO, USA), and $0.1 \%$ (v/v) Triton X-100 (Sigma-Aldrich). Samples were then washed three times for 10 min each in phosphate-buffered saline (PBS) and stored in PBS containing $0.1 \%(\mathrm{w} / \mathrm{v})$ paraformaldehyde at $4{ }^{\circ} \mathrm{C}$ until use.

Cotyledons were immersed in Tissue-Tek (Sakura Finetek USA, Inc., Torrance, CA, USA) and frozen at $-20^{\circ} \mathrm{C}$. Longitudinal sections of $30 \mu \mathrm{m}$ were obtained in a cryomicrotome CH1510-1 (Leica Microsystems GmbH Wetzlar, Germany) and mounted on Menzel-Gläser Superfrost Ultra Plus slides (Thermo-Scientific, Waltham, Massachusetts, USA), which were conserved at $-20^{\circ} \mathrm{C}$ until analysis.

\section{Immunolocalization using benzyl adenosine (BAR), DHZR and iPA polyclonal antibodies}

Immunolocalization of benzyl adenosine (BAR), DHZR and iPA was performed according to the method described by De Diego et al. (2013). About five cotyledons detached from different embryos were used for each treatment. Sections of cotyledon tips were washed in PBS for 1 min, dehydrated in an ascendant ethanol series $(25 \%, 50 \%, 75 \%$ and $100 \%, \mathrm{v} / \mathrm{v})$ for $5 \mathrm{~min}$ each, and then rehydrated in a descendant ethanol series $(100 \%, 75 \%, 50 \%$ and $25 \%$, v/v) for 5 min each. Finally, sections were washed in PBS containing $0.1 \%$ (v/v) Tween 20 for $30 \mathrm{~min}$, and then in PBS for $5 \mathrm{~min}$.

Sections were treated with blocking solution ( $5 \%$ bovine serum albumin (BSA) in PBS, w/v) to reduce nonspecific binding for $30 \mathrm{~min}$. Then, samples were incubated with BAR, DHZR and iPA polyclonal primary antibodies (Agrisera, Vännäs, Sweden) overnight at $4{ }^{\circ} \mathrm{C}$. Dilutions $1 / 50$ in $1 \% \mathrm{BSA} / \mathrm{PBS}$ were used for BAR and DHZR primary antibodies, and dilution 1/100 in 1\% BSA/PBS was used for iPA primary antibody. After washing twice with $0.1 \%$ (v/v) Tween 20 in PBS for 10 min, sections were incubated with Alexa Fluor 488 goat anti-rabbit secondary antibody (Life technologies, Carlsbad, California, USA) diluted $1 / 25$ in $1 \%$ BSA/PBS for $1 \mathrm{~h}$ in darkness. Sections with only secondary antibody and without antibodies were also included as negative controls to assess nonspecific binding and tissue autofluorescence, respectively. Two wash steps with $0.1 \%$ $(\mathrm{v} / \mathrm{v})$ Tween 20 in PBS for 10 min were carried out to reduce nonspecific binding. Sections were then incubated with 4,6-diamidino-2-phenylindole (DAPI; AppliChem GmbH, Darmstadt, Germany) $1 \mu \mathrm{g} \mathrm{mL}^{-1}$ for $15 \mathrm{~min}$. Finally, sections were washed three times with autoclaved $\mathrm{ddH}_{2} \mathrm{O}$ for 5 min, air-dried and mounted with Mowiol ${ }^{\circledR}$ 4-88 (AppliChem $\mathrm{GmbH}$ ).

Sections were visualized using a Leica DM2000 fluorescence microscope (Leica Microsystems, Wetzlar, Germany). Fluorescence from the apical portion of three to five cotyledons per treatment was quantified by ImageJ software (https ://fiji.sc/) following the procedure described by Burgess et al. (2010).

\section{Expression analysis of genes putatively involved in shoot apical meristem formation and maintenance during caulogenic induction in Pinus pinea by quantitative real-time PCR (RT-qPCR)}

\section{RNA isolation and CDNA synthesis}

RNA from explants was extracted using the NucleoSpin RNA Plant kit (Macherey-Nagel, Germany) according to the manufacturer's instructions. A microgram of total RNA was reverse transcribed with the High-Capacity cDNA Reverse Transcription Kit (Applied Biosystems Inc., Foster City, CA, USA) following the manufacturer's protocol.

\section{RT-qPCR}

Based on the role in SAM formation and maintenance, the expression pattern of three WOX genes (PpWOX5, PpWOXX and $P p W U S$; Acc. ALN42234, ANC94876 and ALN42231, respectively), four class I KNOX genes (PpKN1-KN4; Acc. KT356208, KT356209, KT356211 and KT356210, respectively), PipiRR1 (Acc. FJ717710) and PipiCLVIL (Acc. HQ377525) was analyzed during in vitro caulogenic induction by RT-qPCR. Two ESTs (Pp4C3 and Pp5F10; Acc. EC611869 and EC428628, respectively) were used as endogenous reference genes, as had been shown to be constitutively expressed during this process (Cortizo et al. 2010). RT-qPCR was performed in an ABI PRISM 7900HT instrument (Applied Biosystems). Individual reactions were assembled in triplicate with oligonucleotide primers $(0.20 \mu \mathrm{M}$ each), $5 \mu \mathrm{L}$ of Fast SYBR Green Master Mix (Applied) plus $100 \mathrm{ng}$ of cDNA in a final volume of $10 \mu \mathrm{L}$. Primers for each gene were designed with Primer3 software (Rozen and Skaletsky 2000) to amplify a fragment between 60 and $150 \mathrm{bp}$ of the target cDNA with a $60{ }^{\circ} \mathrm{C}$ Tm and a $\mathrm{G}+\mathrm{C}$ content of $40-60 \%$ (Udvardi et al. 2008) (Online 
Resource 1). Amplifications were performed using the following standard protocol: $95{ }^{\circ} \mathrm{C} 20 \mathrm{~s}, 45$ cycles of $95{ }^{\circ} \mathrm{C} 1 \mathrm{~s}$ and $60{ }^{\circ} \mathrm{C} 20 \mathrm{~s}$, with a final melting curve analysis to dismiss the presence of non-specific products. Negative controls (no template) and RT-controls (non-retrotranscribed RNA) were also included to assess amplification product specificity.

Data analysis was performed according to the comparative Ct method (Livak and Schmittgen 2001) through LinRegPCR software, incorporating the mean PCR efficiencies of the target and endogenous genes in the plate. Relative abundance of each transcript was calculated as the mean of three technical replicates and normalized to the mean expression value of the reference genes in each sample.

\section{Data analysis}

A randomized experimental design was applied (Compton 1995) to study the quantitative variables. Three independent experiments were carried out, with three samples per time point that were taken from different culture vessels. The statistical analysis was performed by the Kruskal-Wallis test for independent samples using the SPSS Statistics software (Chicago, IL, USA).

In addition, multivariate analyses of the endogenous hormonal content and gene expression data were performed. PGRs content and gene expression data were analyzed by principal component analysis (PCA), and a partial least squares (PLS) regression was performed for the integration of hormonal content and gene expression data to find the relationships between both datasets. For convenience, data were grouped into two categories for each treatment: short culture times, including samples from 0 to 1 day $\left(\mathrm{BA}_{\mathrm{ST}}\right.$ and $\mathrm{C}_{\mathrm{ST}}$ ), and long culture times, including samples from 2 to 6 days $\left(\mathrm{BA}_{\mathrm{LT}}\right.$ and $\left.\mathrm{C}_{\mathrm{LT}}\right)$. Both PCA and PLS analyses were performed through R software v3.5.1 (https://www.r-proje ct.org/).

\section{Results}

\section{Analysis of the endogenous content and distribution of different plant growth regulators (PGRs) during caulogenic induction in Pinus pinea}

The overall dynamics of PGR content in BA-treated and control cotyledons over different culture times are shown in Fig. 1. BA endogenous levels presented the biggest differences between explants cultivated in the presence and absence of BA. It showed a significant increase in BAtreated cotyledons, with maximum levels at $12 \mathrm{~h}$, and then decreased until 2 days, with a non-significant slight increase afterward. The free base cytokinins DHZ and iP showed non-significant similar dynamics in BA-treated and control cotyledons, while $\mathrm{tZ}$ and iPA presented a higher concentration in control cotyledons at 6 days. Regarding other ribosylated forms, DHZR and tZR content was stable during caulogenic induction in both types of explant.

Regarding auxins, it is remarkable that, at 2 days of induction, the IAA content increased in BA-treated cotyledons with respect to control cotyledons. No significant differences between control and BA-treated cotyledons were found for the brassinosteroid $\mathrm{BK}$ along the process. In the case of $\mathrm{GA}_{4}$, its levels were unaltered in control cotyledons along the process, whereas they were reduced in the presence of BA from 0.5 to 1 days.

Three PGRs involved in plant stress responses were analyzed in this study: ABA, JA and SA. General trends were very similar under both BA-treated and control cotyledons. In detail, a significant reduction of ABA levels was observed after 0.25 days in both treatments, being maintained at similar levels throughout the whole process. JA reached a peak at 1 day in both treatments, and then showed a significant decrease in case of BA-treated cotyledons, with a progressive reduction in control cotyledons. Concerning SA levels, a reduction was observed from 0.5 days on in both control and BA-treated cotyledons, which was more pronounced in the latter case. Whereas SA levels kept reducing progressively throughout the experiment in control cotyledons, a significant rise was observed in BA-treated cotyledons from 4 days on.

To study the hormonal profile that defines each culture stage, the relative content of each hormone was calculated. As expected, BA showed the highest proportion in BAtreated cotyledons, reached a maximum at 0.5 days $(98.75 \%)$ and maintained more than $97 \%$ throughout the experiment, whereas in the control cotyledon case, BA only represented $6 \%$ ( 0.25 days) to $20 \%$ ( 1 days) (data not shown). To compare both types of explants, the percentage of each PGR excluding BA was obtained (Fig. 2). In this case, $\mathrm{GA}_{4}$ was the most abundant PGR, followed by SA and BK. Regarding cytokinins, in the beginning ribosides were more abundant than free bases, keeping this dynamic along the process in both control and BA-treated cotyledons. In fact, iP, DHZ and $\mathrm{tZ}$ constituted the lowest content from all PGRs studied.

\section{PGR immunolocalization during adventitious caulogenesis in Pinus pinea}

Immunolocalization of BAR, DHZR and iPA, performed in the tip of cotyledons, supported the data obtained through UHPLC-MS/MS to a great extent, with some differences probably due to the area of analysis, as it was only focused on the apical part, instead of the whole cotyledon (Fig. 3).

In general terms, BAR showed higher levels in BAtreated cotyledons, with a maximum peak at 2 days, 

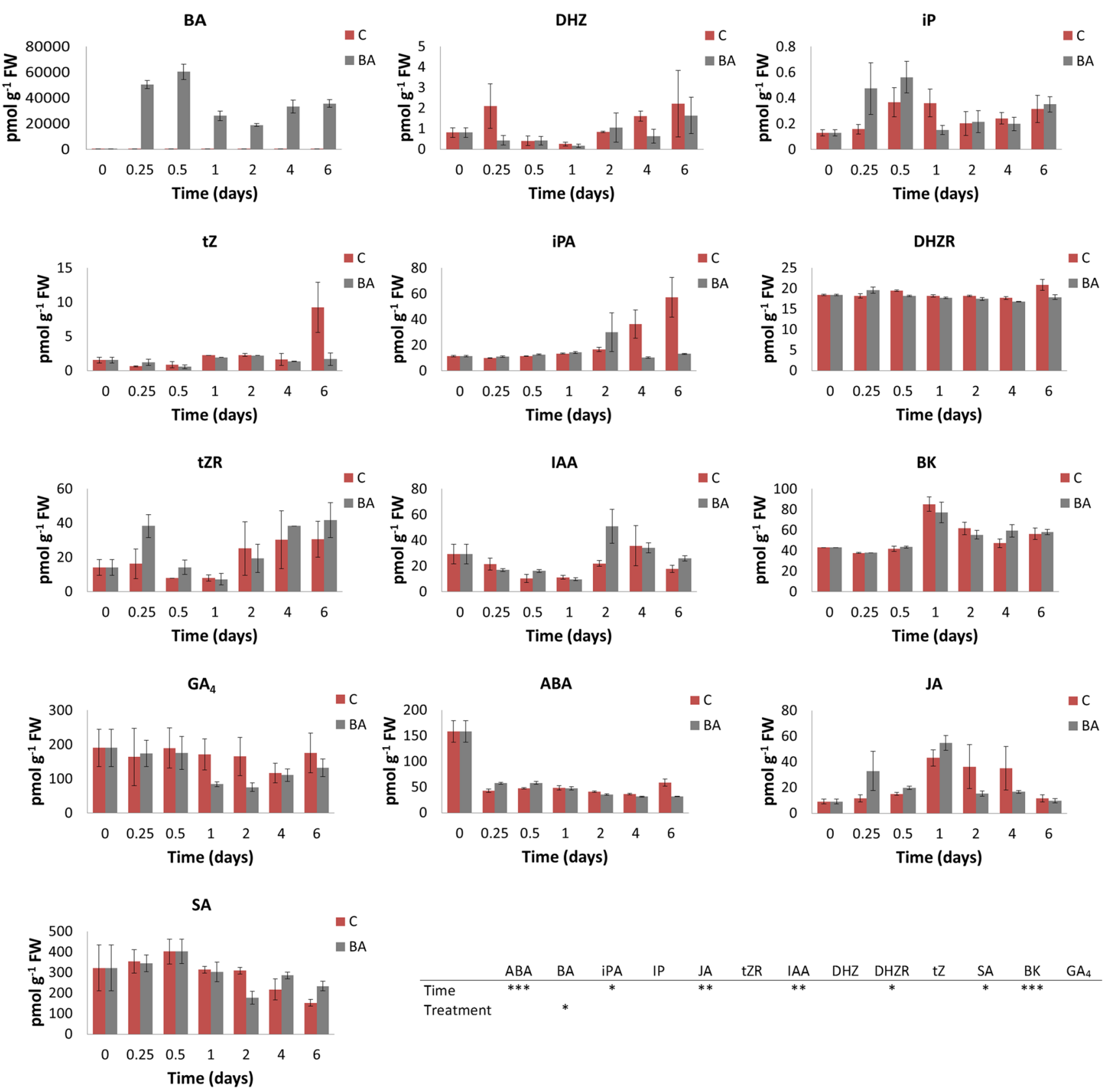

Fig. 1 Content profile of the main plant growth regulators (PGRs), extracted from Pinus pinea cotyledons cultured in the presence of benzyladenine (BA-treated cotyledons, BA) and absence of exogenous hormone (control cotyledons, C): $B A$ benzyladenine, $D H Z$ dihydrozeatin, $D H Z R$ dihydrozeatin riboside, $t Z$ trans-zeatin, $t Z R$ trans-zeatin riboside, $i P$ isopentenyl adenine, $i P A$ isopentenyl adeno- sine, IAA indoleacetic acid, $G A_{4} \mathrm{BK}$ castasterone, gibberellin $\mathrm{A} 4$, abscisic acid, ABA; jasmonic acid, JA; salicylic acid, SA. Results are expressed as mean values \pm standard error. Quantitative data were analyzed by Kruskal-Wallis test. Asterisks indicate significant differences between treatments or times of culture $(* P \leq 0.05$; $* * P$ $\leq 0.01 ; * * * \leq 0.001$ meanwhile DHZR showed variability in its response, with no clear differences between treatments. In regard to iPA, samples showed a rise along the first period ( $0-2$ days), with a decrease observed at 6 days, especially pronounced in the control ones.

\section{Expression analysis of genes putatively involved in shoot apical meristem formation and maintenance during caulogenic induction in Pinus pinea by quantitative real-time PCR (RT-qPCR)}



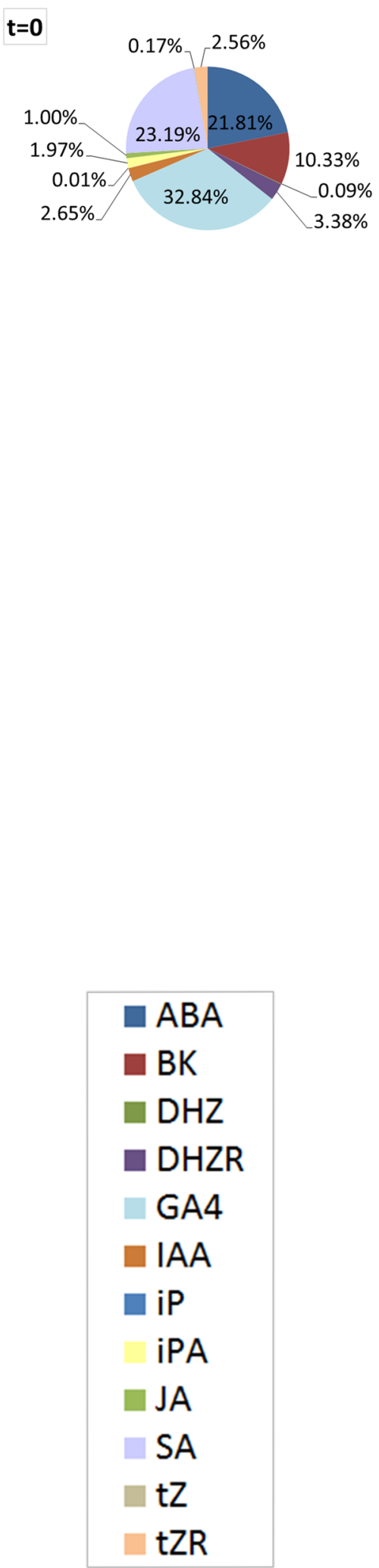
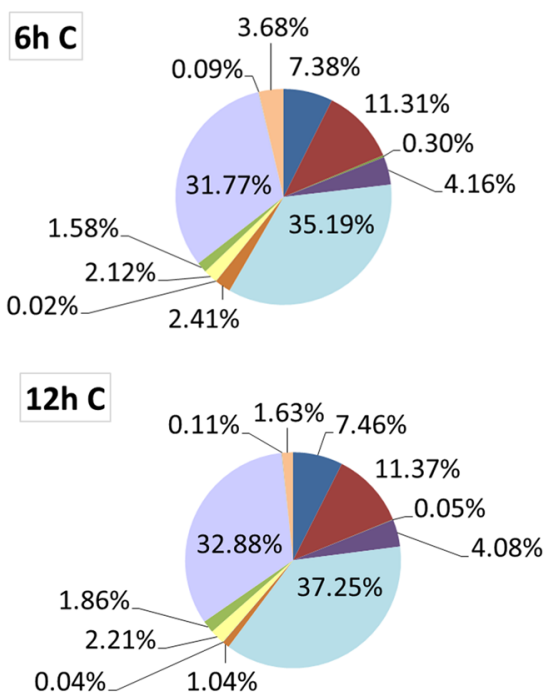

1d C
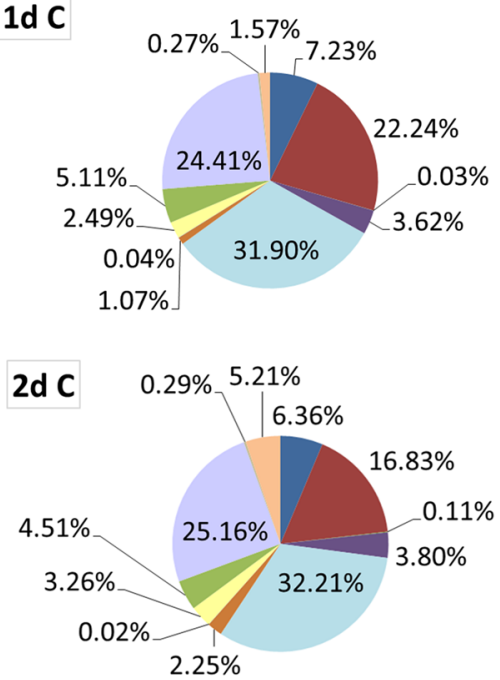

4d C

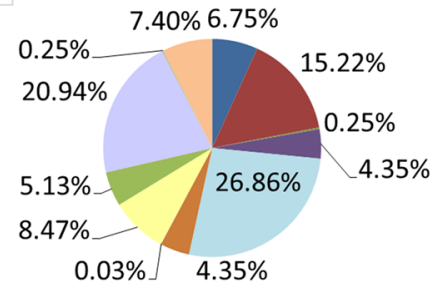

$6 \mathrm{~d} C$

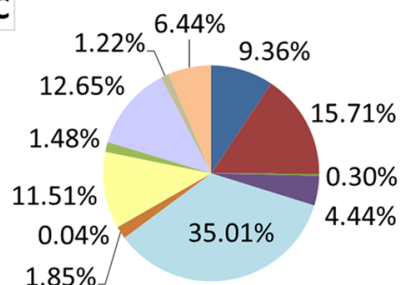

6h BA
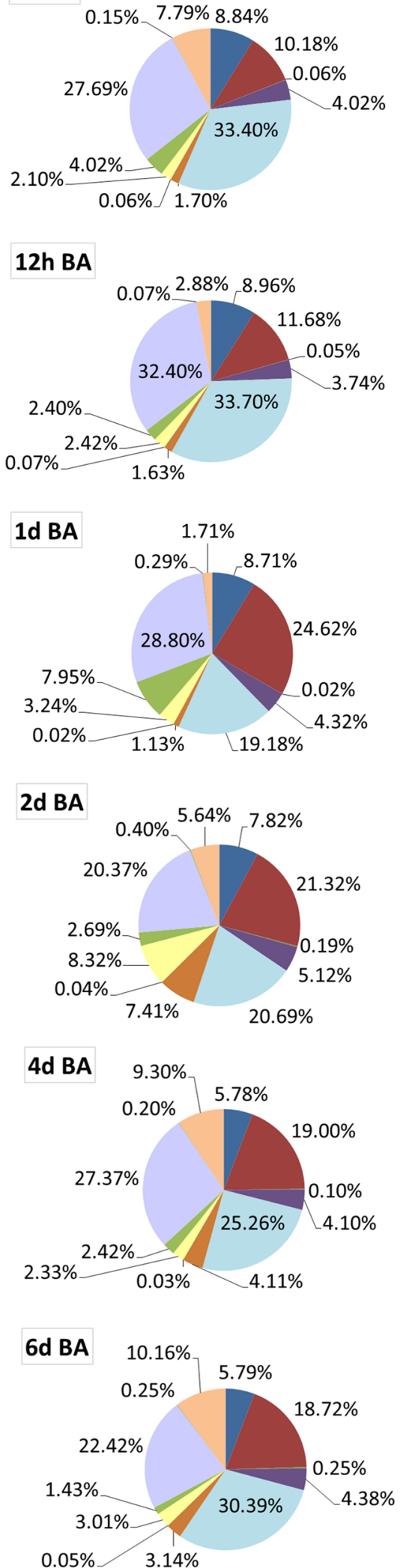

Fig. 2 Proportion of different plant growth regulators (PGRs) during de novo shoot formation in Pinus pinea expressed in percentage of each hormone with respect to the total of tested compounds and excluding benzyladenine (BA) (color figure online) 


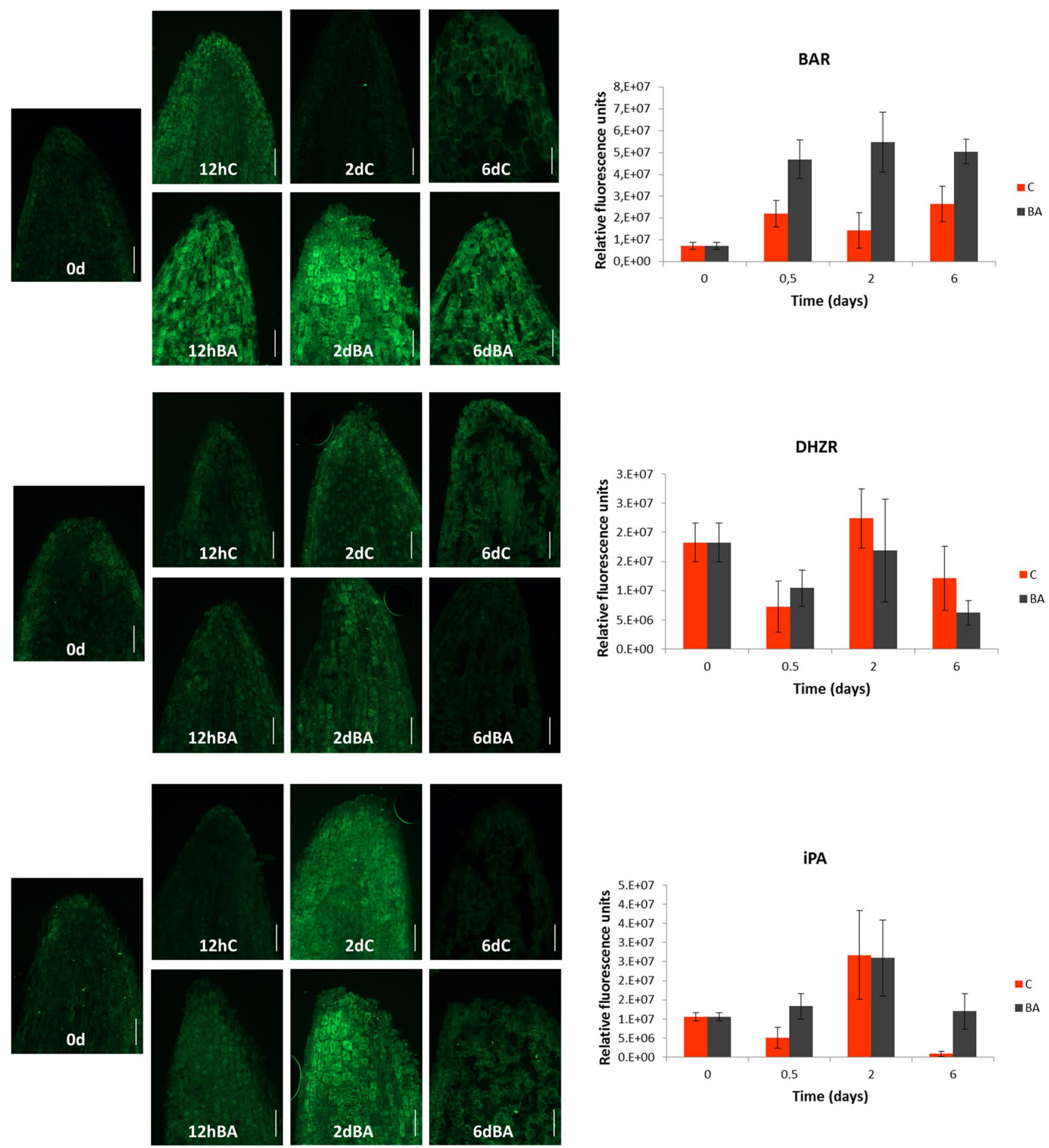

Fig. 3 Immunodetection of benzyl adenosine (BAR), dihydrozeatin riboside (DHZR) and isopentenyl adenosine (iPA) in longitudinal sections of Pinus pinea cotyledons cultured in the presence and absence of benzyladenine (BA) during 0 day, 12 h, 2 days and 6 days. Alexa 488 secondary antibody (green signal) was used. Fluorescence

Results of the expression analysis of three genes from the WOX gene family (PpWUS, PpWOXX and PpWOX5), the quantification was performed following the procedure described by Burgess et al. (2010) through ImageJ software (https://fiji.sc/). BAtreated cotyledons (BA): black bars; non-treated cotyledons (C): red bars. Results are expressed as the mean of the fluorescence values \pm standard error from 3-5 cotyledons per treatment. Bar, $100 \mu \mathrm{m}$

four class I KNOX genes (PpKN1-PpKN4), PipiRRl, and PipiCLVIL are shown in Fig. 4. 

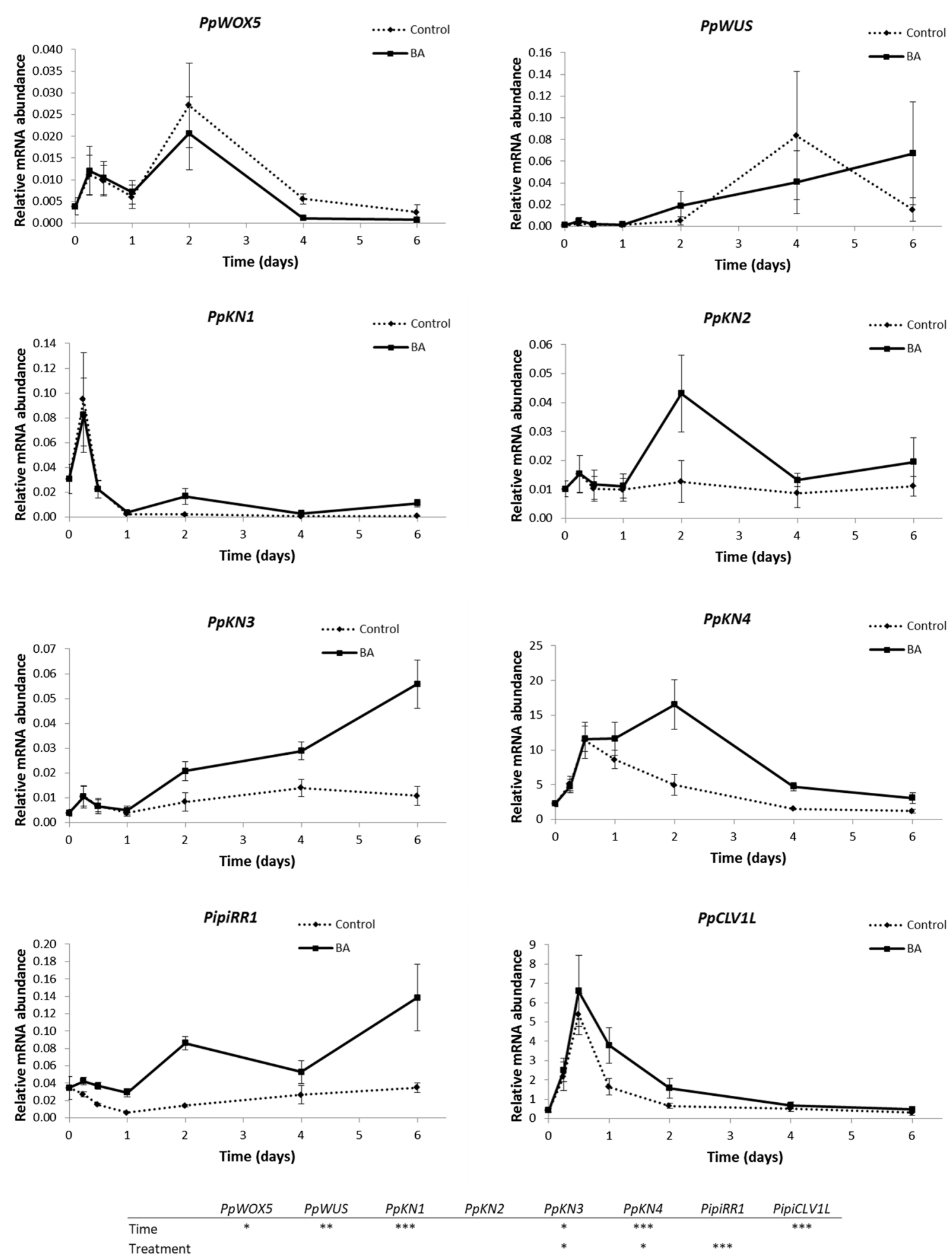

Fig. 4 Quantitative real-time (RT-qPCR) analysis of the mRNA abundance of several members from WOX (PpWOX5, PpWUS) and KNOX (PpKN1, PpKN2, PpKN3, PpKN4) gene families, RESPONSE REGULATOR1 (PipiRR1) and CLAVATA1-LIKE (PipiCLVIL) in Pinus pinea cotyledons cultured in the presence and absence of benzyladenine (BA) during the induction phase of adventitious caulogenesis. Results are expressed as mean values of the relative expression \pm standard error. Quantitative data were analyzed by Kruskal-Wallis test. Asterisks indicate significant differences between treatments or times of culture $(* P \leq 0.05 ; * * P \leq 0.01$; $* * * P \leq 0.001$ 
The mRNA level of PpWUS increased progressively and significantly during the organogenic process in BAtreated cotyledons, showing an erratic pattern in control cotyledons. Levels of PpWOX5 transcripts increased during the first hours of culture in control and BA-treated cotyledons, with a later decrease in both types of explant. In regard to $P p W O X X$ expression, it was below the detection limit for most samples (data not shown).

Overall, $P p K N$ genes seemed to be upregulated in the presence of BA. PpKN1 levels underwent an important increase at 0.25 days, with a later dramatic drop in both types of explants. Regarding PpKN2, whereas its levels were maintained quite constant in control cotyledons, its expression increased at 2 days of culture in BA-treated cotyledons, followed by a slight decrease and then remained upregulated in the presence of BA. PpKN3 expression levels were very similar in BA-treated and control cotyledons during the first hours of culture, and increased progressively and significantly from 1-2 days on in BA-treated cotyledons. For its part, $P p K N 4$ expression reached a significant peak at 2 days of culture in BA-treated cotyledons. Then, its levels decreased and remained about two to three times upregulated in the presence of the hormone.

The gene PipiRRl was significantly upregulated in the presence of BA along the process. Finally, in the case of PipiCLVIL expression, it showed a significant increase during the first hours of culture in control and BA-treated cotyledons, with a later decrease for both types of material, being more pronounced in control cotyledons.

\section{Multivariate analyses of endogenous hormonal content and gene expression data}

The PCA analyses of PGRs content and gene expression data revealed clear differences between short ( $0-1$ days) and long (2-6 days) times of culture (Fig. 5). Whereas no differences were found between control and BA-treated cotyledons at short times, both treatments clustered separately for long times. These differences were mainly explained by BA, BK and IAA for PGR content PCA, and PpWUS, PpKN2, $P p K N 3$ and PipiRR1 for gene expression PCA.

PLS regression analysis of PGR content and gene expression data showed that samples cultured in the presence of BA during long times (2-6 days) clustered separately from the rest of the samples. This distribution was mainly explained by the PGRs tZ, DHZ, iPA, tZR and IAA, and the genes PpWUS, PpWOX5, PpKN2, PpKN3 and PipiRR1 (Fig. 6). It is also remarkable that samples cultured in the presence and absence of BA during short times ( $0-1$ days) grouped together, and stress-related PGRs (ABA, JA and SA), GA and $\mathrm{P}$ were mainly responsible for this distribution.

\section{Discussion}

In vitro caulogenesis in P. pinea, which consists of the development of adventitious buds on the surface of cotyledons cultured in a BA-containing medium, is a method used for the micropropagation of selected genotypes on a large scale (Alonso et al. 2006), but it also constitutes an ideal model for the study of the underlying processes of the SAM

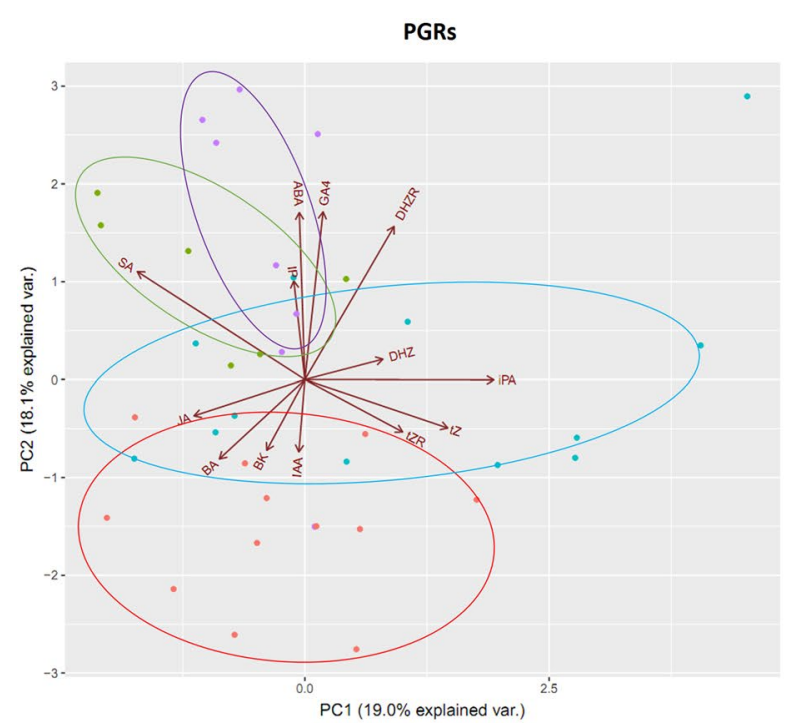

Fig. 5 Analysis of PGRs content and gene expression data by principal component analysis (PCA). $\mathrm{BA}_{\mathrm{ST}}$ : short times (0-1 days), BAtreated cotyledons (green); $\mathrm{BA}_{\mathrm{LT}}$ : long times (2-6 days), BA-treated

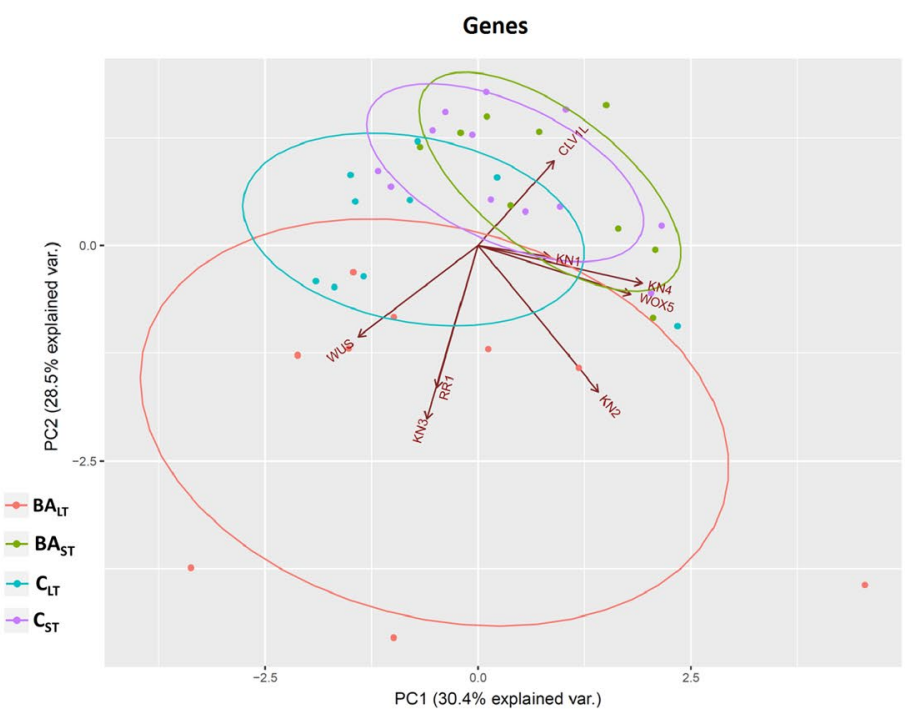

cotyledons (red); $\mathrm{C}_{\mathrm{ST}}$ : short times (0-1 days), control cotyledons (purple); $C_{\mathrm{LT}}$ : long times (2-6 days), control cotyledons (blue) (color figure online) 

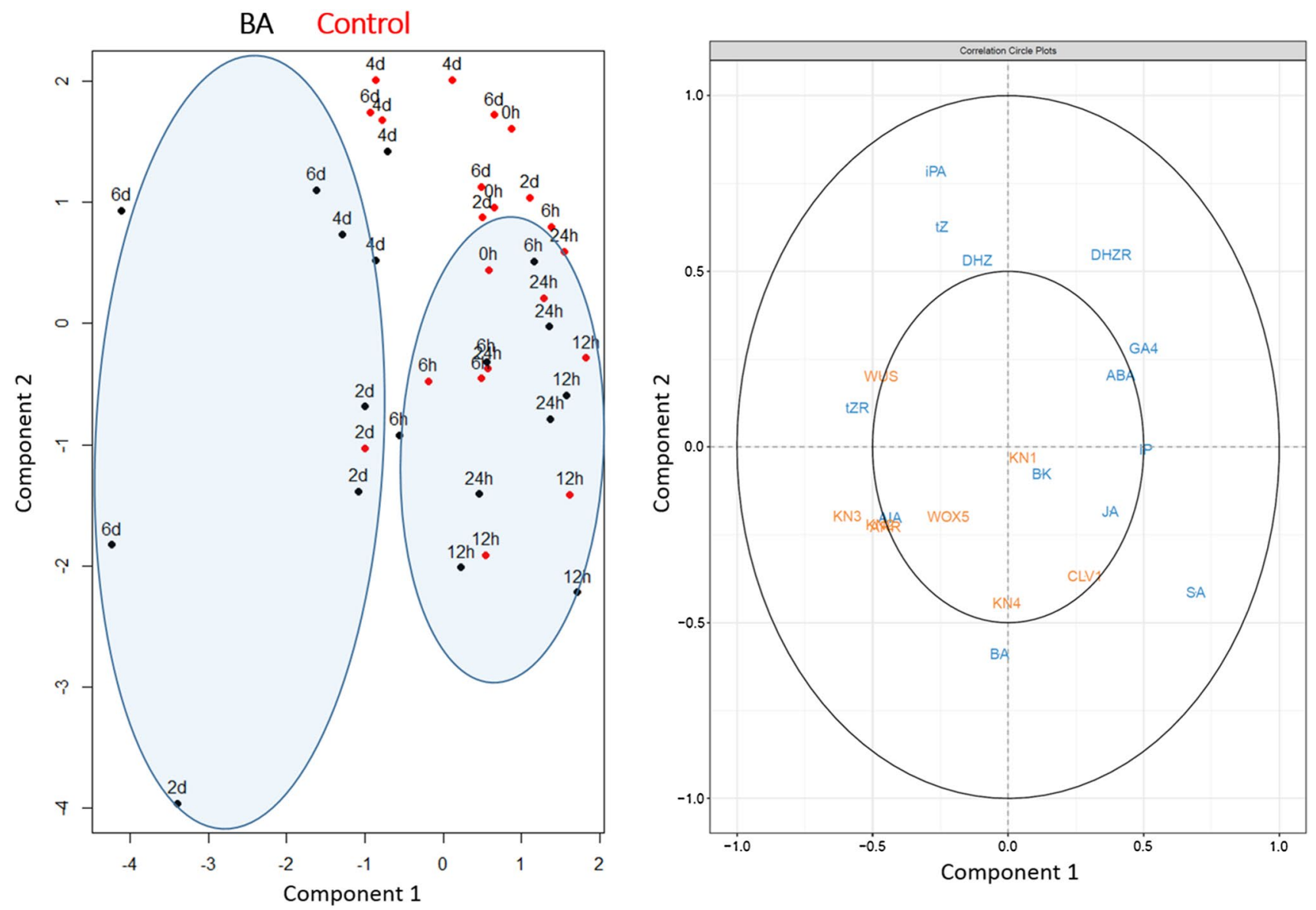

Fig. 6 Correlation loading plot obtained by partial least squares (PLS) regression using plant growth regulator content as the $X$ matrix and gene expression data as the $Y$ matrix

formation and maintenance in conifers (Valdés et al. 2001; Moncaleán et al. 2005). Similar to Arabidopsis, $P$. pinea shoot organogenesis in tissue culture is a multistep process (Moncaleán et al. 2005; Cuesta et al. 2009). However, there are key differences between both species, which may alter the underlying physiological and genetic programs. Whereas shoot regeneration in Arabidopsis is an indirect process, it has been reported that $P$. pinea cotyledons are competent per se to respond to organogenic signals and become committed to shoot regeneration (Cortizo et al. 2009; Cuesta et al. 2009). Therefore, it is unknown if the models of genic expression during angiosperm development may be applicable to conifers.

Previous works support the hypothesis that differences in hormonal contents may induce shoot organogenesis (Cuesta et al. 2012). The present data will help to understand the behavior of gene expression profiles related to caulogenic induction, connecting their response magnitude with the PGRs levels.

The minimum induction period for $P$. pinea cotyledons cultured in a medium containing $44.4 \mu \mathrm{M} \mathrm{BA}$ is 0.25 days and the maximum response is achieved after 2-4 days of BA exposure (Moncaleán et al. 2005; Cuesta et al. 2009). In these conditions, promeristemoids, later developing into meristemoids and shoot primordia, are present at 0.5 days in BA-treated cotyledons, and its appearance is preceded by intense mitotic activity (Cuesta et al. 2009). This indicates that shoot commitment or induction, in which the fate of competent cells is specified for the formation of shoot buds, takes place in the first hours of culture in the presence of BA. In addition, the application of this PGR would only be necessary in the first hours of culture to induce caulogenesis (Cortizo et al. 2009; Cuesta et al. 2009). Consistently with these results, a huge increase of the endogenous BA levels in BA-treated cotyledons was observed during the first hours of culture, which is due to the high absorption rate of exogenous BA (Cuesta et al. 2009). Similar to Cuesta et al. (2009) observations, three phases could be distinguished during caulogenic induction based on BA dynamics: (i) from 0 to 0.5 days, characterized by a high BA uptake rate, reaching the upper peak of BA content, which is fitting with the presence of the first promeristemoid structures; (ii) from 
0.5 to 2 days, characterized by a pronounced decrease in BA concentration; and (iii) from 2 to 6 days, when BA levels slightly increased again.

Despite the relevance of the BA increase during the first hours of culture in BA-treated cotyledons, multivariate analyses (PLS regression and PCA) showed that the main differences for most PGRs and genes analyzed between control and BA-treated cotyledons were found at longer culture times (from 2 days on), suggesting that the initial BA peak triggers the caulogenic response through later changes in other PGRs and gene expression levels. In particular, BAtreated cotyledons cultivated during long times in the induction medium constituted a clearly separated cluster. Based on PLS regression results, this distribution was mainly explained by the cytokinins iPA, tZ, tZR and DHZR, the auxin IAA, and the genes PpWUS, PpWOX5, PpKN2, PpKN3 and PipiRR1.

The ribosides iPA and $\mathrm{tZR}$ and the free bases $\mathrm{tZ}$ and DHZ might perform a relevant role in the caulogenic process. iPA is considered the precursor in the isoprenoid cytokinin biosynthetic pathway and it was previously reported to replace $\mathrm{BA}$ as inducer of the morphogenic responses (Charrière et al. 1999; Cuesta et al. 2012). Free bases are highly active forms, especially $\mathrm{tZ}$, and it has been proposed that they are rapidly used during caulogenic induction, preventing their accumulation at high levels (Moncaleán et al. 2005; Stirk et al. 2005; Cuesta et al. 2012).

The participation of IAA in caulogenic induction in $P$. pinea could be related to the response of the explant to exogenous BA application to reach an optimum cytokinin:auxin ratio for de novo meristem formation. It was established that endogenous auxins together with cytokinins play a key role in initiation and proliferation of meristems, as increasing or decreasing the ratio of cytokinin:auxin in the culture medium induced the regeneration of shoots or roots, respectively (Skoog and Miller 1957). In Arabidopsis, it has been reported that genes involved in auxin biosynthesis are induced during the incubation in the cytokinin-rich medium (Cheng et al. 2013) in a non-overlapping region with the cytokinin response domain, although the role of auxins during shoot regeneration is not completely established (Sang et al. 2018; Ikeuchi et al. 2019). Our results showed that the level of IAA increased in BA-treated cotyledons after active free cytokinins such as BA, in agreement with other authors who found a similar increase of endogenous IAA levels in explants during adventitious organogenesis in other species (Mercier et al. 2003; Malá et al. 2006).

Regarding PGRs involved in stress tolerance, no dramatic changes were observed in their content between BA-treated and non-treated cotyledons along the organogenic process. This is in concordance with Pérez-Jiménez et al. (2014), who did not find any significant differences in JA content in Prunus persica cultures with different organogenic capacity.
Interestingly, these PGRs could be responsible for grouping together cotyledons cultured in the presence and absence of BA at short times according to the multivariate analysis results. This could be due to the fact that cotyledon excision from mature embryos and transference to an artificial culture media cause a stress that affects their hormonal profile. On the other hand, it seems that the application of a very high exogenous BA concentration in the medium with a high rate of absorption did not trigger specific stress tolerance responses in BA-treated explants. Overall, it seems that stress-related PGRs do not have a main role in caulogenesis in this species. Similarly, $\mathrm{GA}_{4}$ and iP levels were slightly affected by BA treatment along the process, but both PGRs contributed to the distribution mentioned above. The brassinosteroid BK could play some role at long times according PCA. However, this role could not be exclusive for BA-treated cotyledons, since no significant differences in BK content were found between control and BA-treated cotyledons at long times.

Some members from WOX and KNOX gene families seem to play a key role during caulogenesis in $P$. pinea, similar to Arabidopsis (Ikeuchi et al. 2019). At short culture times, no big differences between control and BA-treated cotyledons were found for most of them, since only a small number of cells within the explant respond to the induction signal (Thorpe 1980; Alonso et al. 2007). As expected, the peak of BA preceded the increase in the expression of several of the genes analyzed in this work. PLS regression and PCA analyses suggest a pivotal role for PpWUS, PpWOX5, $P p K N 2, P p K N 3$ and PipiRR1 in the caulogenic process. In Arabidopsis, WOX 5 expression is induced during acquisition of competence in the auxin-rich medium (Sugimoto et al. 2010), but caulogenesis in $P$. pinea is a direct process without an intermediate callus phase. Although it has been proposed that $P p W O X 5$ participates in RAM organization in conifers, expression of this gene was detected in other tissues apart from root tips such as shoot apexes, hypocotyls and cotyledons (Alvarez et al. 2018). Therefore, WOX5 could perform additional roles to those traditionally described in angiosperms.

Several class I KNOX genes were shown to have an important role in caulogenic induction. Analysis of STM expression during adventitious caulogenesis in Arabidopsis revealed that it was expressed at low levels during CIM incubation and also upregulated during SIM incubation at the time of shoot commitment (Cary et al. 2002). Based on PCA and PLS regression analyses, the main differences between control and BA-treated cotyledons for long times of culture were caused by $P p K N 2$ and $P p K N 3$ genes. Class I $K N O X$ gene expression was analyzed during somatic embryogenesis in Picea abies to determine their specific roles during SAM formation (Larsson et al. 2012): KN3 ortholog was expressed in somatic embryogenic lines able 
to develop fully mature cotyledonary embryos and inhibited in lines with altered SAM development, suggesting that this gene is essential for SAM formation. Conversely, the $P$. abies $K N 2$ ortholog was shown to be upregulated before SAM formation during somatic embryogenesis both in competent and non-competent embryogenic lines, indicating that this gene has a wider general role during embryogenesis. Our results showed that $P p K N 2$ reached a peak in BA-treated cotyledons at 2 days of culture, coinciding in the time when cells become determined to develop and differentiate into adventitious shoots (Cuesta et al. 2009). This could suggest an important role in caulogenic determination. Regarding $P p K N 3$, its increased levels in the presence of BA after the caulogenic determination might indicate that this gene is involved in meristem organization. Type-A response regulators are upregulated during de novo shoot formation in Arabidopsis (Che et al. 2002), acting as negative regulators of cytokinin signaling and its expression is rapidly induced by this PGR (D'Agostino et al. 2000). The role of PipiRRI in adventitious caulogenesis in $P$. pinea was previously reported by Cortizo et al. (2010), and confirmed in the present report.

In conclusion, the results of this work demonstrate that cytokinins play an active role during the in vitro induction and formation of adventitious shoot meristemoids in cotyledons of $P$. pinea, suggested by the initial peak of BA triggering the response through subsequent changes in other PGRs and levels of gene expression. The most relevant factors involved in this process are cytokinins $t Z$, DHZ, tZR and iPA; the auxin IAA; and the genes $P p W U S$, PpWOX5, PpKN2, PpKN3 and PipiRR1. PpWUS is functional in pines and has an important role in caulogenesis. Interestingly, $P p W O X 5$ also seems to participate in the process, although its specific function has not been determined. The output of the present work revealed the complexity of in vitro caulogenesis in a relatively simple tissue culture system, which provide a useful base for following further investigation of the function and interaction of different PGRs and genes, specifically those from the WOX and KNOX families, elucidating if the model of genic expression during organogenic processes in angiosperm development may be valid in conifers.

Acknowledgements This work was supported by "Instituto Nacional de Investigación y Tecnología Agraria y Alimentaria" (INIA) and "Fondo Europeo de Desarrollo Regional" (FEDER) cofounding (RTA2013-00048-C03-02 and RTA2017-00063-C04-04) and University of Oviedo (PAPI-17-PEMERG-3). NB was funded by a predoctoral grant from "Fundación para el Fomento en Asturias de la Investigación Científica Aplicada y la Tecnología” (FICYT) (BP10-098).

Author contributions The design of the study was made by RJO and the experimental setup was planned by RJO, JMA and NB. NB performed most of the experimental work. RJO, JMA, CC, IF and NB analyzed and interpreted the data. NB drafted the manuscript. All authors revised and approved the final manuscript.

\section{Compliance with ethical standards}

Conflict of interest The authors declare that they have no conflict of interest. All authors revised and approved the final manuscript.

Open Access This article is licensed under a Creative Commons Attribution 4.0 International License, which permits use, sharing, adaptation, distribution and reproduction in any medium or format, as long as you give appropriate credit to the original author(s) and the source, provide a link to the Creative Commons licence, and indicate if changes were made. The images or other third party material in this article are included in the article's Creative Commons licence, unless indicated otherwise in a credit line to the material. If material is not included in the article's Creative Commons licence and your intended use is not permitted by statutory regulation or exceeds the permitted use, you will need to obtain permission directly from the copyright holder. To view a copy of this licence, visit http://creativecommons.org/licenses/by/4.0/.

\section{References}

Aitken-Christie J, Singh AP, Davies H (1988) Multiplication of meristematic tissue: a new tissue culture system for radiata pine. In: Hanover IW, Keathley DE (eds) Genetic manipulation of woody plants. Plenum Press, New York, pp 413-432. https://doi. org/10.1007/978-1-4613-1661-9_26.

Alonso P, Moncaleán P, Fernández B, Rodríguez A, Centeno ML, Ordás RJ (2006) An improved micropropagation protocol for stone pine (Pinus pinea L.). Ann For Sci 63:879-885. https://doi. org/10.1051/forest:2006071

Alonso P, Cortizo M, Cantón FR, Fernández B, Rodríguez A, Centeno ML, Cánovas FM, Ordás RJ (2007) Identification of genes differentially expressed during adventitious shoot induction in Pinus pinea cotyledons by subtractive hybridization and quantitative PCR. Tree Physiol 27:1721-1730. https://doi.org/10.1093/treep hys/27.12.1721

Alvarez JM, Cortizo M, Bueno N, Rodríguez A, Ordás RJ (2013) CLAVATA1-LIKE, a leucine-rich-repeat protein receptor kinase gene differentially expressed during adventitious caulogenesis in Pinus pinaster and Pinus pinea. Plant Cell Tiss Org 112(3):331342. https://doi.org/10.1007/s11240-012-0240-8

Alvarez JM, Bueno N, Cañas RA, Avila C, Cánovas FM, Ordás RJ (2018) Analysis of the WUSCHEL-RELATED HOMEOBOX gene family in Pinus pinaster: new insights into the gene family evolution. Plant Physiol Biochem 123:304-318. https://doi. org/10.1016/j.plaphy.2017.12.031

Belmonte M, Tahir M, Schroeder D, Stasolla C (2007) Overexpression of $H B K 3$, a class I KNOX homeobox gene, improves the development of Norway spruce (Picea abies) somatic embryos. J Exp Bot 58:2851-2861. https://doi.org/10.1093/jxb/erm099

Burgess A, Vigneron S, Brioudes E, Labbé J-C, Lorca T, Castro A (2010) Loss of human Greatwall results in G2 arrest and multiple mitotic defects due to deregulation of the cyclin B-Cdc2/PP2A balance. Proc Natl Acad Sci USA 107:12564-12569. https://doi. org/10.1073/pnas.0914191107

Cary AJ, Che P, Howell SH (2002) Developmental events and shoot apical meristem gene expression patterns during shoot development in Arabidopsis thaliana. Plant J 32:867-877. https://doi. org/10.1046/j.1365-313X.2002.01479.x 
Charrière F, Sotta B, Miginiac E, Hahne G (1999) Induction of adventitious shoots or somatic embryos on in vitro cultured zygotic embryos of Helianthus annuus: variation of endogenous hormone levels. Plant Physiol Biochem 37:751-757. https://doi. org/10.1016/s0981-9428(00)86688-7

Che P, Gingerich D, Lall S, Howel SH (2002) Global and hormoneinduced gene expression changes during shoot development in Arabidopsis. Plant Cell 14:2771-2785. https://doi.org/10.1105/ tpc.006668

Cheng ZJ, Wang L, Sun W, Zhang Y, Zhou C, Su YH, Li W, Sun TT, Zhao XY, Li XG, Cheng Y, Zhao Y, Xie Q, Zhang XS (2013) Pattern of auxin and cytokinin responses for shoot meristem induction results from regulation of cytokinin biosynthesis by AUXIN RESPONSE FACTOR3. Plant Physiol 161(1):240-251. https:// doi.org/10.1104/pp.112.203166

Christianson ML, Warnick DA (1983) Competence and determination in the process of in vitro shoot organogenesis. Dev Biol 95:288293. https://doi.org/10.1016/0012-1606(83)90029-5

Compton ME (1995) Statistical methods suitable for the analysis of plant tissue culture data. Plant Cell Tiss Org Cult 37:217-242. https://doi.org/10.1007/978-1-61779-818-4_9

Cortizo M, Cuesta C, Centeno ML, Rodríguez A, Fernández B, Ordás RJ (2009) Benzyladenine metabolism and temporal capacity of Pinus pinea L. cotyledons to form buds in vitro. J Plant Physiol 166:1069-1076. https://doi.org/10.1016/j.jplph.2008.12.013

Cortizo M, Álvarez JM, Rodríguez A, Fernández B, Ordás RJ (2010) Cloning and characterization of a type-A response regulator differentially expressed during adventitious shoot formation in Pinus pinea L. J Plant Physiol 167:1023-1026. https://doi.org/10.1016/j. jplph.2010.02.012

Cuesta C, Ordás RJ, Fernández B, Rodríguez A (2008) Clonal micropropagation of six selected half-sibling families of Pinus pinea and somaclonal variation analysis. Plant Cell Tiss Org 95:125130. https://doi.org/10.1007/s11240-008-9412-y

Cuesta C, Rodríguez A, Centeno ML, Ordás RJ, Fernández B (2009) Caulogenic induction in cotyledons of stone pine (Pinus pinea): relationship between organogenic response and benzyladenine trends in selected families. J Plant Physiol 166:1162-1171. https ://doi.org/10.1016/j.jplph.2009.01.004

Cuesta C, Novák O, Ordás RJ, Fernández B, Strnad M, Doležal K, Rodríguez A (2012) Endogenous cytokinin profiles and their relationships to between-family differences during adventitious caulogenesis in Pinus pinea cotyledons. J Plant Physiol 169:1830-1837. https://doi.org/10.1016/j.jplph.2012.08.012

D'Agostino I, Deruère J, Kieber J (2000) Characterization of the response of the Arabidopsis response regulator gene family to cytokinin. Plant Physiol 124:1706-1717. https://doi.org/10.1104/ pp.124.4.1706

De Diego N, Rodríguez JL, Dodd IC, Pérez-Alfocea F, Moncaleán P, Lacuesta M (2013) Immunolocalization of IAA and ABA in roots and needles of radiate pine (Pinus radiata) during drought and rewatering. Tree Physiol 33:537-549. https://doi.org/10.1093/ treephys/tpt033

Delatorre C, Rodríguez A, Rodríguez L, Majada JP, Ordás RJ, Feito I (2017) Hormonal profiling: development of a simple method to extract and quantify phytohormones in complex matrices by UHPLC-MS/MS. J Chromatogr B 1040:239-249. https://doi. org/10.1016/j.jchromb.2016.11.007

Flinn B, Webb D, Newcomb W (1988) The role of cell clusters and promeristemoids indetermination and competence for caulogenesis by Pinus strobus cotyledons in vitro. Can J Bot 66:1556-1565. https://doi.org/10.1139/b88-214

González MV, Rey M, Tavazza M, La Malfa S, Cuozzo L, Ancora G (1998) Improvement of in vitro adventitious shoot formation on cotyledons of Pinus pinea L. HortScience 33:749-750. https:// doi.org/10.21273/HORTSCI.33.4.749

Guillet-Claude C, Isabel N, Pelgas B, Bousquet J (2004) The evolutionary implications of knox-I gene duplications in conifers: correlated evidence from phylogeny, gene mapping, and analysis of functional divergence. Mol Biol Evol 21:2233-2245. https://doi. org $/ 10.1093 / \mathrm{molbev} / \mathrm{msh} 235$

Hjortswang HI, Sundås-Larsson A, Bharathan G, Bozhkov PV, von Arnold S, Vahala T (2002) KNOTTED1-like homeobox genes of a gymnosperm, Norway spruce, expressed during somatic embryogenesis. Plant Physiol Biochem 40:837-843. https://doi. org/10.1016/S0981-9428(02)01445-6

Ikeuchi M, Favero DS, Sakamoto Y, Iwase A, Coleman D, Rymen B, Sugimoto K (2019) Molecular mechanisms of plant regeneration. Annu Rev Plant Biol 13:54. https://doi.org/10.1146/annurev-arpla nt-050718-100434

Kareem A, Radhakrishnan D, Sondhi Y, Aiyaz M, Roy MV, Sugimoto K, Prasad K (2016) De novo assembly of plant body plan: a step ahead of Deadpool. Regeneration 3:182-197. https://doi. org/10.1002/reg2.68

Larsson E, Sitbon F, von Arnold S (2012) Differential regulation of Knotted1-like genes during establishment of the shoot apical meristem in Norway spruce (Picea abies). Plant Cell Rep 31:10531060. https://doi.org/10.1007/s00299-011-1224-6

Livak KJ, Schmittgen TD (2001) Analysis of relative gene expression data using real-time quantitative PCR and the $2^{-\Delta \Delta \mathrm{Ct}}$ method. Methods 25:402-408. https://doi.org/10.1006/meth.2001.1262

López M, Pacheco J, Rodríguez R, Ordás RJ (1996) Regeneration of plants from isolated cotyledons of salgareño pine (Pinus nigra Arn. ssp. Salzmannii (Dunal) Franco). Vitro Cell Dev-P1 32:109114. https://doi.org/10.1007/BF02823140

Malá J, Gaudinvá A, Dobrev P, Eder J, Cvikrová M (2006) Role of phytohormones in organogenic ability of elm multiplicated shoots. Biol Plant 50:8-14. https://doi.org/10.1007/s10535-005-0068-8

Meng WJ, Cheng ZJ, Sang YL, Zhang MM, Rong XF, Wang ZW, Tang YY, Zhang XS (2017) Type-B ARABIDOPSIS RESPONSE REGULATORs specify the shoot stem cell niche by dual regulation of WUSCHEL. Plant Cell 29:1357-1372. https://doi. org/10.1105/tpc. 16.00640

Mercier H, Souza BM, Kraus JE, Hamasaki RM, Sotta B (2003) Endogenous auxin and cytokinin contents associated with shoot formation in leaves of pineapple cultured in vitro. Braz J Plant Physiol 15:107-112. https://doi.org/10.1590/S1677-0420200300 0200006

Moncaleán P, Alonso P, Centeno ML, Cortizo M, Rodríguez A, Fernández B, Ordás RJ (2005) Organogenic responses of Pinus pinea cotyledons to hormonal treatments: BA metabolism and cytokinin content. Tree Physiol 25:1-9. https://doi.org/10.1093/ treephys/25.1.1

Pérez-Jiménez M, Cantero-Navarro E, Pérez-Alfocea F, Le-Disquet I, Guivarc'h A, Cos-Terrer J, (2014) Relationship between endogenous hormonal content and somatic organogenesis in callus of peach (Prunus persica L. Batsch) cultivars and Prunus persica $\times$ Prunus dulcis rootstocks. J Plant Physiol 171:619-624. https:// doi.org/10.1016/j.jplph.2014.01.006

Rozen S, Skaletsky H (2000) Primer3 on the WWW for general users and for biologist programmers. Methods Mol Biol 132(3):365386. https://doi.org/10.1385/1-59259-192-2:365

Sang YL, Cheng ZJ, Zhang XS (2018) Plant stem cells and de novo organogenesis. New Phytol 218:1334-1339. https://doi. org/10.1111/nph.15106

Shi B, Zhang C, Tian C, Wang J, Wang Q, Xu T, Xu Y, Ohno C, Sablowski R, Heisler MG, Theres K, Wang Y, Jiao Y (2016) Twostep regulation of a meristematic cell population acting in shoot 
branching in Arabidopsis. PLOS Genet 12(7):e1006168. https:// doi.org/10.1371/journal.pgen.1006168

Skalický V, Kubeš M, Napier R, Novák O (2018) Auxins and cytokinins - the role of subcellular organization on homeostasis. Int $\mathrm{J}$ Mol Sci 19(10):3115. https://doi.org/10.3390/ijms19103115

Skoog F, Miller CO (1957) Chemical regulation of growth and organ formation in plant tissue cultures in vitro. Sym Soc Exp Biol 11:118-131

Stirk WA, Gold JD, Novak O, Strnad M, Van Staden J (2005) Changes in endogenous cytokinins during germination and seedling establishment of Tagetes minuta L. Plant Growth Regul 47:1-7. https ://doi.org/10.1007/s10725-005-1767-z

Sugimoto K, Jiao Y, Meyerowitz EM (2010) Arabidopsis regeneration from multiple tissues occurs via a root development pathway. Dev Cell 18:463-471. https://doi.org/10.1016/j.devcel.2010.02.004

Sundås-Larsson A, Svenson M, Liao H, Engström P (1998) A homeobox gene with potential developmental control function in the meristem of the conifer Picea abies. Proc Natl Acad Sci USA 95:15118-15122. https://doi.org/10.1073/pnas.95.25.15118

Thorpe TA (1980) Organogenesis in vitro: structural, physiological and biochemical aspects. In: Vasil IK (ed) Perspectives in plant cell and tissue culture. international review of cytology. Supplement. Academic Press, New York, pp 71-111

Tian X, Zhang C, Xu J (2018) Control of cell fate reprogramming towards de novo shoot organogenesis. Plant Cell Physiol 59(4):713-719. https://doi.org/10.1093/pcp/pcx207

Udvardi MK, Czechowski T, Scheible WR (2008) Eleven golden rules of quantitative RT-PCR. Plant Cell 20(7):1736-1737. https://doi. org/10.1105/tpc. 108.061143
Valdés AE, Ordás RJ, Fernández B, Centeno ML (2001) Relationships between hormonal contents and the organogenic response in Pinus pinea cotyledons. Plant Physiol Biochem 39:377-384. https://doi. org/10.1016/S0981-9428(01)01253-0

Valvekens D, Van Montagu M, Van Lijsebettens M (1988) Agrobacterium tumefaciens-mediated transformation of Arabidopsis thaliana root explants by using kanamycin selection. Proc Natl Acad Sci USA 85:5536-5540. https://doi.org/10.1073/pnas.85.15.5536

Zhang TQ, Lian H, Zhou CM, Xu L, Jiao Y, Wang J (2017) A two-step model for de novo activation of WUSCHEL during plant shoot regeneration. Plant Cell 29:1073-1087. https://doi.org/10.1105/ tpc. 16.00863

Zubo YO, Blakley IC, Yamburenko MV, Worthen JM, Street IH, Franco-Zorrilla JM, Zhang W, Hill K, Raines T, Solano R, Kieber JJ, Loraine AE, Schaller GE (2017) Cytokinin induces genomewide binding of the type-B response regulator ARR10 to regulate growth and development in Arabidopsis. Proc Natl Acad Sci USA 14(29):5995-6004. https://doi.org/10.1073/pnas.1620749114

Publisher's Note Springer Nature remains neutral with regard to jurisdictional claims in published maps and institutional affiliations. 